\title{
Resolution Process of Therapeutic Alliance Ruptures: A Review of the Literature
}

\author{
Pierre Baillargeon ${ }^{1}$, Robert Coté ${ }^{2}$, Lyne Douville ${ }^{1}$ \\ ${ }^{1}$ Université du Québec à Trois-Rivières, Trois-Rivières, Canada \\ ${ }^{2}$ Université de Laval, Québec, Canada \\ Email: pierre.baillargeon@uqtr.ca, Robert.Cote@ulaval.ca, lyne.douville@uqtr.ca
}

Received September $18^{\text {th }}, 2012$; revised October $20^{\text {th }}, 2012$; accepted November $17^{\text {th }}, 2012$

\begin{abstract}
Adolescents living in youth centers often comply with therapeutic treatment against their will. We think that this forced environment ruptures the therapeutic alliance between adolescents and their therapists and, as such, influences the therapeutic results. It has been reported, however, that therapies evoking rupture of the alliance with its later restoration are more effective than therapies without rupture. We review the literature on models of therapeutic alliance rupture resolution. This review is limited to experimentallytested models. Firstly, we define the concepts of therapeutic alliance and its rupture. Then, we explore experimental models that quantify therapeutic alliance rupture resolution, describing methods of experimental validation, the results of models applied for experimental validation, and analysis of the data thus obtained.
\end{abstract}

Keywords: Therapeutic Alliance; Rupture, Resolving; Literature Review; Psychotherapy

\section{Introduction}

Adolescents in youth centers often submit to treatment against their will. Pauzé, Toupin, Déry and Mercier (2000) and Lessard (2001) report that a large number of adolescents in youth centers were placed there in accordance with the Young Offenders Act or the Youth Protection Act. Lessard (2001) specifies that in $1999-2000,48.2 \%$ of referrals were finalized by a judge. Le Blanc, Girard, Kaspi, Lanctôt and Langelier (1995) note that in the Jesness Personality Inventory, adolescents under judicial control have a tendency to be mistrustful and withdrawn in their interactions with others, particularly authority figures. This context may influence the quality of the therapeutic alliance between youths and their caseworkers, and thus affect the results of the intervention.

Yet, quality therapeutic alliances are associated with a wide range of positive results. Researchers like Horvath and Symonds (1991), Martin, Garske and Davis (2000) and Orlinsky, Grawe and Parks (1994), for example, arrive at this conclusion. These researchers evaluated the short- and long-term effects of psychodynamic, cognitive and experimental therapies with clients whose problems varied. Florsheim, Shotorbani, GuestWarnick, Barratt and Hwang (2000), on their part, suggest that young delinquents who develop and maintain a positive therapeutic alliance with their caseworkers show considerable improvement during treatment and less recidivism in the year following treatment.

Ruptures in the therapeutic alliance between youths and their caseworkers seem inevitable in youth center contexts. However, some authors, for example Safran, Crocker, McMain and Murray (1990), argue that therapies that include alliance ruptures appear to be more effective than those without ruptures, on condition, however, that the alliance is restored.

This article reviews experimental models of the resolution process of therapeutic alliance ruptures. Experimental models of the resolution process are interesting because they are likely to propose ways of resolving alliance ruptures to caseworkers. Applying one resolution process model would make interventions more specific and thus increase its effectiveness. First, we want to remind psychosocial workers of the concepts of therapeutic alliance and of therapeutic alliance rupture. Next, we will focus on experimental models of alliance rupture resolution, describing experimental investigation methods, the results of experimental investigation of these models, and analysis of the data.

\section{The Therapeutic Alliance Concept}

The therapeutic alliance concept, which has been the subject of research over the past few decades, specifies the importance of the relationship in successful therapy. The first theoretical and experimental studies on the therapeutic alliance originate primarily from psychodynamic approaches (Luborsky, 1976; Zetzel, 1956) and are client-centred (Rogers, 1957; BarrettLennard, 1962, 1978, 1986). The more recent investigations stem from cognitive and systemic approaches (Pinsof, 1995; Safran \& Muran, 2000). In these studies, there is increasing recognition of the role of the alliance in the effectiveness of therapy. Furthermore, pharmacotherapy considers the alliance as a factor that influences collaboration and, consequently, the results of therapy (Docherty, 1989). Although heterogeneous in terms of change mechanisms, these studies help conceive the importance of the alliance in the change process.

Recognition of the importance of the patient therapist alliance dates back to Freud. In his first papers, Freud $(1913,1966)$ proposed that therapists establish a bond with their patients at the outset of the therapeutic relationship. According to Freud, the patient must be allowed time for this bond to be established. If the therapist shows great interest in the patient, eliminates resistances and avoids certain mistakes, the patient will form an 
attachment to him. This attachment will resemble the one that he has already established with people who have paid attention to him. Freud adds that an intervention can start off badly if, during the first sessions, the therapist does not receive the patient's point of view with sympathetic understanding.

In line with Freud's ideas, authors like Greenson (1965, 1967), Sterba (1934) and Zetzel (1956) pursued studies on the impact of the patient-therapist alliance on the success of an intervention. Sterba (1934) introduced the ego alliance concept in which he refers to the need for a positive relationship between the patient's reasonable ego and the therapist's analyzing ego. The author stresses the importance of the patient's ability to work towards the success of the intervention.

Zetzel (1956) introduced the therapeutic alliance concept, which she believes comprises the patient's positive relationship and identification with the therapist. She sees the therapeutic alliance as a repetition of the parent-child relationship. Zetzel does not define this concept any further, but sees it as an important element in the success of an intervention.

Inspired by Sterba and Zetzel, Greenson $(1965,1967)$ introduced the concept of working alliance, which he uses as a synonym of the therapeutic alliance. Greenson sees the alliance as a positive relationship between patient and therapist and as the patient's ability to work towards the success of the intervention.

In addition to acknowledging the patient's contribution to the alliance, Freud $(1913,1966)$ advanced that the therapist plays a major role in the establishment of an alliance. Rogers (1957) pursued Freud's idea of a patient-centred approach. One of the central concepts of the Rogerian approach is formulated as follows: the relationship offered by the therapist is a necessary condition that is sufficient to help patients resolve their problems. Rogers (1957) and Barrett-Lennard (1962, 1978, 1986) presented the conditions involved in a patient-therapist alliance. They proposed the following hypothesis: empathy, congruence and unconditional acceptance from the therapist suffice for the patient to improve. However, authors like Gelso and Carter (1985) and Mitchell, Bozart and Krauft (1977) believe that the conditions described by Rogers and Barrett-Lennard are not sufficient to ensure the success of an intervention.

Other authors affirm that the concept of the alliance is neither valid nor useful (Brenner, 1979) or that it can be misleading (Curtis, 1979). Brenner (1979) argues that there is no alliance phenomenon. The patient's relationship with the therapist is a phenomenon of transference that must be treated as resistance. The patient's desire to work within treatment can be viewed as a desire to win the approval of a parental figure or to compete with the therapist for his perspicacity. Such transference determinants of the patient's engagement and collaboration in treatment are considered difficult to distinguish from non-conflictual determinants of the alliance. Curtis (1979) believes that the alliance concept represents a danger of moving away from the analytical concepts of unconscious intrapsychic conflicts, of free association and the interpretation of transfer and resistance.

Another controversy pertains to divergent concepts of the alliance. They can be illustrated by the variability in definitions of the alliance. For example, Luborsky (1976) and Zetzel (1956) described the alliance as the patient's bond with the therapist and the therapist's helpfulness as perceived by the patient. However, Frieswyk, Allen, Colson et al. (1986) define the alliance as the patient's active collaboration in treatment tasks. Both definitions of the patient's collaboration in psychotherapy can be conceived as distinct, but relatively dependent, dimensions. The alliance includes the affective aspects of the patient's collaboration in therapy that are aimed at the therapist's person and reflect the more skillful aspects of the patient's collaboration that are directed towards treatment tasks.

\section{Definition of the Therapeutic Alliance}

Bordin (1979) proposes the most recognized concept of the alliance. According to Bordin, the 3 main dimensions of content of the therapeutic alliance are tasks, goals and the bond. Pinsof (1995) describes and illustrates each of these dimensions. The task dimension pertains to the activities or main tasks in which the patient and therapist engage during the intervention. Specifically, it refers to the extent to which a patient believes that the tasks meet his expectations and how comfortable he finds them. If the patient expects to have a conversation with the therapist and the therapist rarely speaks, the therapist's behaviour does not live up to the patient's expectations of the intervention. The patient expects a dialogue while the therapist expects the patient to speak with a minimum of feedback on his part. In this situation, the task components of the alliance will be relatively weak. Comfort in the task dimension refers to the degree of well-being or anxiety that the patient experiences relative to the tasks. For example, the therapist can strongly encourage Louise, a 17-year-old woman hospitalized after a suicide attempt, to tell her elder brothers and sisters and her parents that she was sexually abused by her uncle from the ages of 10 to 14 years. If Louise is too afraid to perform this task, she will be in conflict. The therapist's expectations exceed her comfort threshold. Even if Louise thinks that confiding in her brothers, sisters and parents is a good idea, and even if her expectations for the tasks are congruent with those of the therapist, emotionally, the task may prove beyond her strength at that time. If the therapist insists that she perform this task, the task component of the alliance will be seriously compromised.

The second major dimension of the alliance, the goals, refers to the extent to which the patient experiences a therapist who works with him on the problems for which he requests help: "Is the therapist trying to help him attain his goals?" or "Is the therapist pursuing goals that do not interest him?" For example, parents with marital problems seek help for their son's depression. Since their goal does not consist in improving their marriage, prematurely targeting their marital problems would greatly weaken their alliance and compromise the intervention.

The last dimension of the alliance, the bond, refers to the affective quality of the alliance and includes aspects of the patient-therapist relationship, such as trust, concern and engagement. The bond dimension covers the extent to which the therapist becomes a significant person and an emotionallycharged object for the patient and to which the patient feels that the therapist is committed to and concerned about him. The bond is, therefore, the patient's emotional response to the therapist and his effects.

The 3 work alliance dimensions are interdependent. Consequently, the quality of the relationship mediates the patient's and therapist's ability to negotiate an agreement regarding the intervention tasks and goals. The patient's ability to negotiate such an agreement also mediates the quality of the bond between them.

\section{Predictive Validity of the Therapeutic Alliance}

The capacity of the therapeutic alliance to predict the success 
of a therapy seems to be confirmed. The most frequently-cited meta-analysis of the predictive validity of the alliance is that of Horvath and Symonds (1991). The question at the outset of the meta-analysis is the following: What is the strength of the relationship between the therapeutic alliance and the results of therapy? The study inclusion criteria were the following: 1) the relationship construct measured in the study must be identified by the authors as the working alliance, helping the alliance or therapeutic alliance; 2) the research must concern a quantifiable relationship between the alliance and the indices of subsequently-measured results; and 3) the studies analyzed must involve at least 5 subjects. Finally, only investigations involving an individual treatment (as opposed to group or family therapies) were included. Twenty-four studies met the abovementioned criteria. Effect sizes (ES) for all the data were combined and a weighted ES was calculated (summarizing the relationship between the therapeutic alliance and the results of the therapy). The combined ES was .26. The size was moderate but very significant $(p<.001)$.

Furthermore, the most extensive survey of the predictive factors of psychotherapy results was carried out by Orlinsky, Grawe and Parks (1994). These authors focus on the relationship between the psychotherapeutic approach or specific measures of the therapeutic process and the clinical results. The study inclusion criteria were the following: 1) the studies must comprise real treatments administered to real patients; 2) they must specifically contain therapeutic variables whose changes are measured quantitatively and concomitantly with variations of the results; and 3) they must lend themselves to observation of the relationship between the process and the results. The authors reported 2354 observations on the relationship between the therapeutic process and the clinical results. For the bond and cohesion concepts, 2 concepts of the therapeutic alliance, Orlinsky, Grawe and Parks (1994) listed 132 findings, showing a $66 \%$ significant correlation with the treatment data.

More recently, Martin, Garske and Davis (2000) performed a meta-analysis similar to that of Horvath and Symonds (1991). It comprised 79 studies. The combined ES was .22. The size was moderate and significant $(p<.05)$.

\section{The Concept of Therapeutic Alliance Rupture}

According to Pinsof and Catherall (1986), the alliance is a dynamic phenomenon that differs from one therapeutic system to another and changes within the same system during the intervention. Usually, as the intervention progresses, the alliance becomes more intense. Different types of interventions and different caseworkers form different types of alliances with similar patients. The alliance varies with the intervention phases. A rupture in the alliance between patient and therapist can occur at any time. The rupture is deterioration stemming either from a disagreement on the goals and tasks or from a problem related to the bond. Such a rupture fractures the alliance and creates a decisive moment in the relationship between the patient and therapist.

Alliance ruptures can cause the premature end of interventions. Disruptions in the alliance may be too great and become irreparable for several reasons. Patients may be too narcissistically vulnerable to manage their disappointment and may reject the treatment. The therapist's response may not be empathetic enough with the patient's experience and may thus increase the fracture and sabotage the treatment. Last, the therapist's mistake may be so evident and disturbing that the patient's escape becomes a sound, adaptive response to the therapist's non-ethical, non-professional or incompetent behaviour (Figure 1).

\section{Types of Ruptures}

Safran and Muran (2000) identify 2 types of ruptures: withdrawal and confrontation. In withdrawal ruptures, the patient withdraws and partially disengages from the therapist, his own emotions or certain aspects of the therapeutic process. Withdrawal ruptures can take different forms. In some cases, the patient has difficulty expressing his concerns or needs in the relationship. For example, one patient expresses his concerns indirectly or attenuates them. In other cases, the patient submits or adapts to the therapist's desire so subtly that the therapist may have trouble recognizing the patient's adaptation.

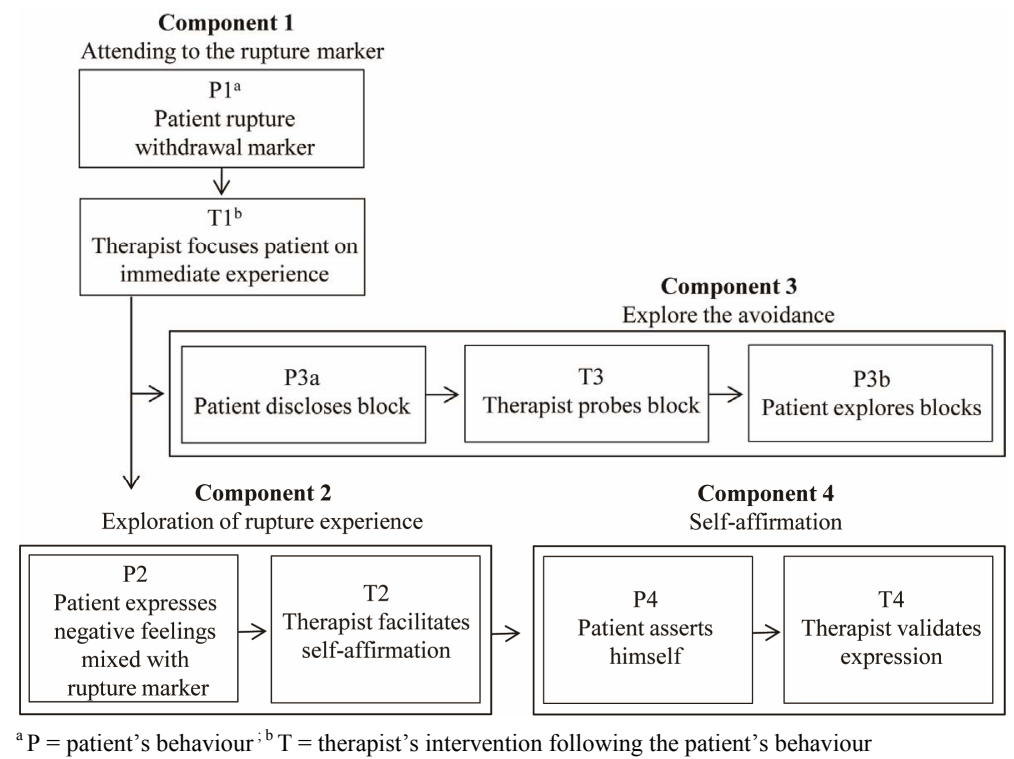

Figure 1.

Illustrates Model 2. 
In confrontation ruptures, the patient directly expresses anger or resentment, as well as his dissatisfaction with regard to the therapist or certain aspects of the therapy. For example, one patient has long had a desire for support that has not been filled or a desire to be cared for and a tendency to see the therapist as one more person who will disappoint him. He therefore enters into the therapeutic relationship with a pool of disappointment and rage, waiting to be aroused by the therapist's inevitable mistakes and limitations. When a confrontation rupture occurs, it may be difficult, if not impossible, for the therapist to avoid responding defensively to the patient's demands or criticisms; he thus receives the expected response from the other. It often happens that a therapist's interpretations subtly convey messages of blame and depreciation to his patients, or that these interpretations are complex communications that simultaneously translate messages of help and of criticism.

Withdrawal and confrontation ruptures reflect the various ways that a patient can face tension between the dialectically-opposed needs for individualization and relationships. In withdrawal ruptures, patients fight for the relationship at the expense of their need for individualization or self-definition. In confrontation ruptures, patients negotiate the conflict while favouring the need for individualization or self-definition to the detriment of their need for a relationship. Different patients probably have a predominance for one style of rupture rather than another; this predominance reflects different styles of adaptation. Both types of ruptures (withdrawal and confrontation) can emerge during treatment.

Given the importance of the therapeutic alliance in the results of therapy, it seems imperative to clarify the process involved in resolving therapeutic alliance ruptures.

\section{Experimental Model of Alliance Rupture Resolution}

The question at the outset of the review is the following: Which models of the alliance rupture resolution process were subjected to experimental investigation? To answer this question, we performed a computerized search in the following electronic data banks: PsycINFO, ERIC, PsycLIT and Medline. These data banks contain publications from the fields of psychology and related sciences. They compile thousands of periodicals in several languages from various countries. They refer also to books, theses and technical reports as well as book chapters. The descriptors are: restor ${ }^{*}$ or ruptur ${ }^{*}$ or poor or conflict ${ }^{*}$ or resolution or problematic or strain ${ }^{*}$ or weak ${ }^{*}$ or viable or repair ${ }^{*}$ or reestablish ${ }^{*}$ and therapeutic alliance or working alliance or helping alliance. Document references are a second source for locating studies. To be included in the review, studies had to present experimental investigation of a model of the alliance rupture resolution process or of the help relationship in a context of psychotherapeutic intervention or psychosocial intervention.

The computerized search generated 43 studies. Of this number, 5 met the inclusion criteria: 2 by Safran and Muran (1996), 1 by Safran, Muran and Samstag (1994) and 2 by Inck (1995). The particularity of studies that were not retained $(n=38)$ was that they did not include experimental investigations of a rupture resolution process. They were mainly theoretical papers on the therapist-patient relationship or experimental studies on factors that influence the therapist-patient relationship. This review did not consider models such as in Aspland et al. (2008) or Bennett, Parry and Ryle (2006) where they developed only the first steps of the Task analysis by Greenberg (1984b) and Rice and Greenberg (1984).

In all studies retained (Safran \& Muran, 1996; Safran, Muran, \& Samstag, 1994; Inck, 1995), experimental investigation was carried out on the same alliance rupture resolution model: Safran, Muran and Samstag's Model 2 (1994).

Safran, Muran and Samstag's (1994) Model 2 comprises 4 components. The first, second and fourth include an intervention by the therapist that follows behaviour by the patient. The third component includes patient behaviour, an intervention by the therapist and, once again, patient behaviour.

The first component $(\mathrm{C} 1$, pay attention to the withdrawal rupture indicator) includes P1 (the patient produces a withdrawal rupture indicator) followed by $\mathrm{T} 1$ (the therapist focuses the patient on his immediate experience). One patient's behaviour suggests that he is avoiding exploration of certain feelings (P1). The therapist draws attention to what is currently happening between them (T1). There are several ways the therapist can conduct this intervention. For example, he may ask questions about the patient's current experience, such as: "What are you feeling now?"

The second component ( $\mathrm{C} 2$, exploration of the rupture experience) includes P2 (the patient expresses negative feelings mixed with the indicator) followed by T2 (the therapist facilitates self-affirmation). In response to the therapist's intervention intended to draw the patient's attention to their current relationship (T1), the patient expresses negative feelings but with some reserve (P2). The therapist intervenes so that the patient expresses his negative feelings more directly (T2). For example, the therapist tells the patient that he feels he has been on the defensive since the beginning of the therapy (T1). The patient then acknowledges that he is starting to feel a bit of anger towards the therapist (P2). The therapist responds to the expression of negative feelings either by showing empathy or by accepting his responsibility for contributing to the interaction (T2). For example, in 1 session, the patient asks the therapist if he is criticizing him. The therapist admits to having criticized him, which can break the impasse.

The third component (C3, exploration of avoidance) includes, respectively, P3a (the patient reveals the block), T3 (the therapist asks questions about the patient's block) and P3b (the patient explores the fear that prevents him from expressing negative feelings). In response to the therapist's intervention intended to draw the patient's attention to their current relationship (T1), the patient begins to reveal his hesitations about discussing his negative feelings, either by anticipating this perspective or by exploring and expressing his experience (P3a). The therapist delves deeper into what is blocking the patient (T3). Typically, in response to the patient's difficulties expressing his negative feelings (P3a), the therapist directly questions the patient's fears that block him from expressing his feelings (T3). For example, the patient feels anger towards the therapist but holds back from saying so (P1). In response to the therapist's questions about what is currently happening between them (T1), the patient indicates that he feels anxiety at the thought of mentioning it (P3a). The therapist then inquires about the nature of this anxiety, asking the patient what is worrying him (T3). The therapist's questioning allows the patient to explore his fear of expressing his negative feelings (P3b). For example, the patient explores his fear of being abandoned by the therapist if he expresses his negative feelings toward 
him.

The fourth component (C4, self-affirmation) includes P4 (the patient asserts himself) and T4 (the therapist validates the self-affirmation). The patient is then able to express his feelings more directly and self-assertively. For example, the patient expresses, hesitantly, the frustration that he felt during the previous session (P2). The therapist intervenes so that the patient expresses his negative feelings more directly (T2). Gradually, as the patient expresses feelings more directly (P4), the therapist approves (T4). The patient thus manages to assert himself in his interactions with the therapist.

Safran, Muran and Samstag (1994) developed Model 2 with adaptation of the task analysis method employed by Greenberg (1984), Safran, Greenberg and Rice (1988), Rice and Greenberg (1984) and Rice and Saperia (1984). The analysis method comprises 3 major steps. The first step of the analysis method consists in developing a preliminary model of the resolution process based on psychotherapy theories and the researchers' intuitions (Safran, Segal, Hill, \& Whiffen, 1990). In the preliminary model, an intervention by the therapist follows the patient's behaviours. Figure 2 presents the preliminary resolution process model.

In the second step, the researchers perform an informal analysis of the preliminary model by comparing it with the content of the psychotherapy sessions in which resolved ruptures are found (the method for selecting resolved rupture sessions will be described in the next section). They identify the gaps between model components and the content of resolved rupture sessions and refine the preliminary model accordingly. They thus obtain Safran, Muran and Samstag's (1994) Model 1. The researchers develop operational definitions of the components of Model 1 with a battery of process measurements: subscales from the Structural Analysis of Social Behavior (SASB) (Benjamin, 1974, 1979, 1982), codes from the Patient Experiencing Scale (P-EXP) (Klein, Mathieu-Coughlan, \& Kiesler, 1986) and from the Therapist Experiencing Scale (T-EXP) (Klein, Mathieu-Coughlan, \& Kiesler, 1986) and, finally, the tone of voice with the Client Vocal Quality Scale (CVQ) (Rice $\&$ Kerr, 1986). Figure 3 presents Model 1.

Finally, at the third step, the researchers perform a descriptive analysis of Model 1 . They analyze 4 resolution sessions and 3 non-resolution sessions by comparing the frequency of the components and subcomponents of the model. The analysis enables them to refine Model 1 and arrive at Model 2. The first refinement of Model 1 for rupture resolution involves the third component (C3, Exploration of the avoidance). In its original design, the component included 2 subcomponents. Analysis suggests the following sequence: recognition of the patient's block, the therapist's questions, and the patient's exploration. The second refinement involves the fourth component ( $\mathrm{C} 4$, Exploration of the interpersonal pattern). Since the researchers did not find 2 occurrences of this component, they did not consider it an essential part of the resolution process. The fourth component becomes the patient's affirmation.

\section{Description of the Experimental Investigation Methods}

The researchers subject the sequences proposed by Model 2 to experimental investigation. They adopt 2 processes. The first consists in verifying the transitional probabilities of the model only in alliance rupture resolution sessions. Safran, Muran and
Samstag (1994) engage this process. The second process consists of verifying the transitional probabilities of the model in resolution and non-resolution sessions and comparing the results. Safran and Muran (1996) and Inck (1995) used this process. Table 1 summarizes the methodological elements of the studies.

The number of resolution and non-resolution sessions used by the researchers varies between 3 and 4 . To evaluate rupture resolution or non-resolution in the sessions, the researchers score 6 items from the Working Alliance Inventory (WAI) (Horvath, 1994; Safran, Muran, \& Samstag, 1994). After each session, patients and therapists fill out the questionnaire for the beginning, middle and end of the session, for each of the items. When the patient's and therapist's evaluations become weaker in the middle than at the beginning and the end of the session $(+$, $-,+)$, the authors note a deterioration in the relationship and a resolution of the rupture. When the patient's and therapist's evaluations become weaker in the middle and at the end than at the beginning of the session $(+,-,-)$, the authors note a deterioration in the relationship and rupture resolution. The researchers consider differences of more than $20 \%$.

Studies by Safran, Muran and Samstag (1994) and Inck (1995) involved 3 therapists who held a Ph.D., a master's degree or a clinical psychology license. Safran and Muran (1996) give no information about the therapists. The number of patients varied from 3 to 5 adults. The diagnoses were the following: depressive symptoms, major depression, anxiety, dysthymia, agoraphobia, cannabis addiction and various personality disorders. Safran and Muran's (1996) studies do not describe the patients' diagnoses. Some sessions involve the same therapist or patient.

Safran, Muran and Samstag (1994), Safran and Muran (1996) and Inck (1995) in their first study employed the same instruments to measure the process as those used for Model 1: SASB, P-EXP, T-EXP, CVQ. Inck's (1995) second study examined an instrument developed by the author: direct identification of the resolution components (DIRC). Weighted coefficients for the resolution and non-resolution sessions vary from .61 to .84 for SASB, from .70 to .95 for P-EXP, from .66 to .80 for T-EXP, from .36 to .55 for CVQ and from .46 to .75 for DIRC. Safran, Muran and Samstag (1994), Safran and Muran (1996) and Inck (1995) for their first study give no indication of the validity of their instruments. In his second study, Inck evaluated the validity of his system of categories by comparing the DIRC codes with the SASB, P-EXP, T-EXP and SVQ codes. Inck gives a validity coefficient varying from .76 to .90 for the DIRC.

\section{Results of Transitional Probabilities of the Model}

Safran and Muran (1996), Safran, Muran and Samstag (1994) and Inck (1995) performed sequential analyses to evaluate the transitional probabilities suggested by the model, both within components (P1-T1; P2-T2; P3a-T3-P3b; P4-T4) and between components (C1-C2; C1-C3; C2-C4). Table 2 presents the results of transitional probabilities of the resolution model.

The results of Safran, Muran and Samstag's (1994) sequential analyses do not appear in Table $\mathbf{1}$ because the authors assign $\mathrm{z}$ scores rather than probabilities, as in the 4 other studies. Safran, Muran and Samstag (1994) performed sequential analyses only on alliance rupture sessions. All sequences within 


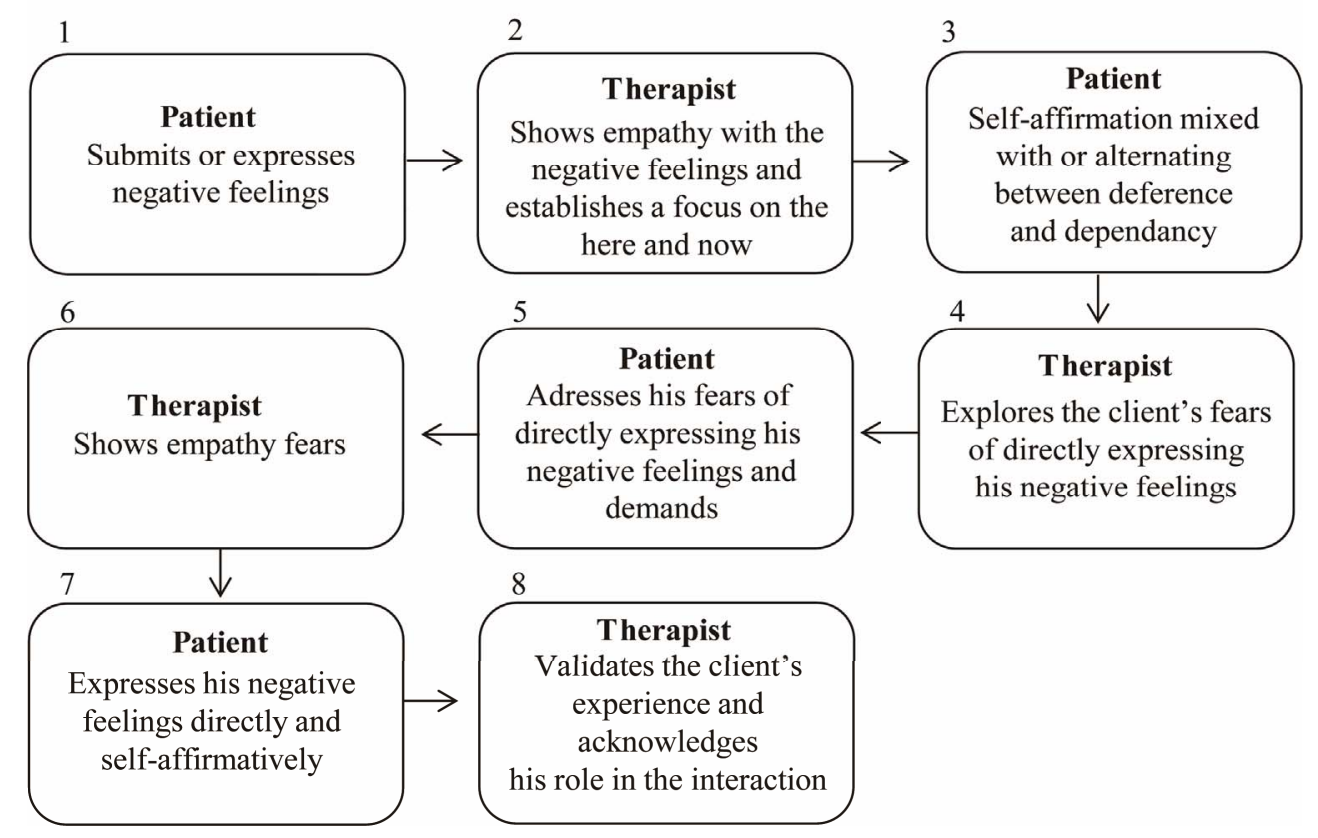

Figure 2.

The preliminary resolution process model.

\section{Component 1}

Attending to the rupture marker

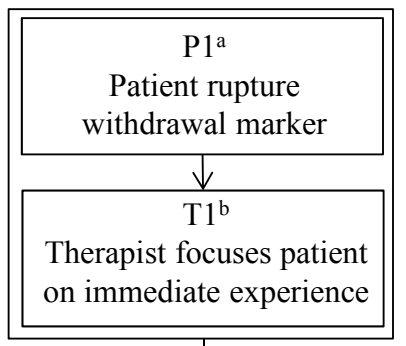

\section{Component 2}

Exploration of the rupture experience

\begin{tabular}{|c|}
\hline $\begin{array}{c}\text { P2 } \\
\text { Patient expresses } \\
\text { negative feelings }\end{array}$ \\
$\downarrow$ \\
$\mathrm{T} 2$ \\
$\begin{array}{c}\text { Therapist empathizes and/or } \\
\text { accepts responsibility }\end{array}$ \\
\hline
\end{tabular}

\section{Component 3}

Exploration of the avoidance

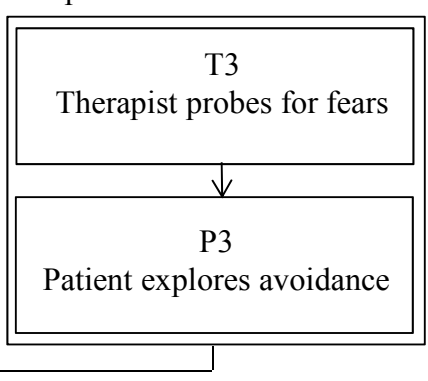

\section{Component 4}

Exploration of interpersonal schema

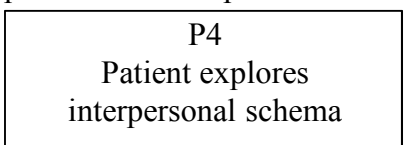

${ }^{\mathrm{a}} \mathrm{P}=$ patient's behaviour ${ }^{\mathrm{b}} \mathrm{T}=$ therapist's intervention following the patient's behaviour.

Figure 3.

Model 1. 
Table 1.

Methodological elements of the studies.

\begin{tabular}{|c|c|c|c|c|c|c|c|}
\hline \multirow{2}{*}{ Studies } & \multirow{2}{*}{ Processes } & \multicolumn{2}{|c|}{ Session } & \multicolumn{2}{|c|}{ Dyads } & \multicolumn{2}{|c|}{ Process measurement instruments ${ }^{2}$} \\
\hline & & $\mathrm{R}^{1}$ & NR & Therapist (T) & Patient $(\mathrm{P})$ & Reliability & Validity \\
\hline $\begin{array}{c}\text { Safran \& } \\
\text { Muran's } \\
\text { (1996) study } 1\end{array}$ & $\begin{array}{l}\text { Compare alliance rupture } \\
\text { resolution sessions to } \\
\text { non-resolution sessions }\end{array}$ & 4 & 3 & $\begin{array}{l}\text { Number and training not } \\
\text { available } \\
\text { Experiential and } \\
\text { cognitive approach }\end{array}$ & Not available & $\begin{array}{cc}\text { SASB } & .69-.84 \\
\text { P-EXP } & .89-.70 \\
\text { T-EXP } & .66-.79 \\
\text { VQC } & .43-.55\end{array}$ & Not available \\
\hline $\begin{array}{c}\text { Safran \& } \\
\text { Muran's } \\
\text { (1996) study } 2\end{array}$ & $\begin{array}{l}\text { Compare alliance rupture } \\
\text { resolution sessions to } \\
\text { non-resolution sessions }\end{array}$ & 4 & 4 & $\begin{array}{l}\text { Number and training not } \\
\text { available } \\
\text { Experiential and } \\
\text { cognitive approach }\end{array}$ & Not available & $\begin{array}{cl}\text { SASB } & .61-.67 \\
\text { P-EXP } & .89-.82 \\
\text { T-EXP } & .70-.80 \\
\text { VQC } & .36-.41\end{array}$ & Not available \\
\hline $\begin{array}{l}\text { Safran, Muran, } \\
\text { \& Samstag } \\
\text { (1994) }\end{array}$ & $\begin{array}{l}\text { Verify the transitional } \\
\text { probabilities of Model } 2 \text { in } \\
\text { alliance rupture resolution } \\
\text { sessions }\end{array}$ & & 4 & $\begin{array}{l}\text { T1 Ph.D. and cognitive } \\
\text { approach } \\
\text { T2 Master's and } \\
\text { cognitive approach } \\
\text { T3 Master's and } \\
\text { cognitive approach }\end{array}$ & $\begin{array}{l}\text { P1 depression symptoms } \\
\text { P2 depression symptoms } \\
\text { and anxiety } \\
\text { P3 interpersonal problems }\end{array}$ & $\begin{array}{lr}\text { SASB } & .69 \\
\text { P-EXP } & .83-.95 \\
\text { T-EXP } & .72-.79 \\
\text { VQC } & .55\end{array}$ & Not available \\
\hline $\begin{array}{l}\text { Inck's (1995) } \\
\text { study } 1\end{array}$ & $\begin{array}{l}\text { Compare alliance rupture } \\
\text { resolution sessions to } \\
\text { non-resolution sessions }\end{array}$ & 3 & 3 & $\begin{array}{l}\text { T1 Ph.D. and cognitive } \\
\text { approach } \\
\text { T2 Ph.D. and cognitive } \\
\text { approach } \\
\text { T3 license and cognitive } \\
\text { approach }\end{array}$ & $\begin{array}{l}\text { P1 depressive disorder, } \\
\text { obsessive compulsive and } \\
\text { dependent personality. } \\
\text { P2 dysthymia, cannabis } \\
\text { addiction and personality } \\
\text { disorder. } \\
\text { P3 major depression, ago- } \\
\text { raphobia, obsessive com- } \\
\text { pulsive and passive aggres- } \\
\text { sive personality. }\end{array}$ & $\begin{array}{c}\text { SASB } .69-.78 \\
\text { P-EXP } .81-.92 \\
\text { T-EXP } .73-.78 \\
\text { VQC } .38-.43\end{array}$ & Not available \\
\hline $\begin{array}{l}\text { Inck (1995) } \\
\text { study } 2\end{array}$ & $\begin{array}{l}\text { Compare alliance-rupture } \\
\text { resolution sessions }\end{array}$ & 3 & 3 & $\begin{array}{l}\text { Same therapists as in } \\
\text { Inck's (1995) study } 1\end{array}$ & $\begin{array}{l}\text { Same subjects as in Inck's } \\
\text { (1995) study } 1\end{array}$ & DIRC $.46-.75$ & DIRC $.76-.90$ \\
\hline
\end{tabular}

Note: ${ }^{1} \mathrm{R}=$ alliance rupture resolution session; $\mathrm{NR}=$ alliance rupture non-resolution session, ${ }^{2} \mathrm{SASB}=$ Structural Analysis of Social Behavior (Benjamin, $\left.1974,1979,1982\right)$; $\mathrm{P}-\mathrm{EXP}=$ Patient Experiencing Scale (Klein, Mathieu-Coughlan \& Kiesler, 1986); T-EXP = Therapist Experiencing Scale (Klein, Mathieu-Coughlan, \& Kiesler, 1986); $\mathrm{CVQ}=$ Client Vocal Quality Scale (Rice \& Kerr, 1986)

Table 2.

Results of transitional probabilities of the resolution model.

\begin{tabular}{|c|c|c|c|c|c|c|c|c|}
\hline \multirow[t]{3}{*}{ Sequences } & \multicolumn{4}{|c|}{ Safran \& Muran (1996) } & \multicolumn{4}{|c|}{ Inck (1995) } \\
\hline & \multicolumn{2}{|c|}{ Study 1} & \multicolumn{2}{|c|}{ Study 2} & \multicolumn{2}{|c|}{ Study 1} & \multicolumn{2}{|c|}{ Study 2} \\
\hline & Resolution & Non-resolution & Resolution & Non-resolution & Resolution & Non-resolution & Resolution & Non-resolution \\
\hline $\mathrm{P} 1 \rightarrow \mathrm{T} 1^{\mathrm{a}}$ & $1.00^{* * *}$ & $.92^{* *}$ & $1.00^{* * *}$ & $1.00^{* * *}$ & $1.00^{* * *}$ & $1.00^{* * *}$ & $1.00^{* * *}$ & $1.00^{* * *}$ \\
\hline $\mathrm{P} 2 \rightarrow \mathrm{T} 2$ & $.87^{* * *}$ & $.67^{* * *}$ & $.96^{* * *}$ & $.67^{* * *}$ & $.96^{* * *}$ & $.67^{* * *}$ & $.97^{* * *}$ & $.47^{* * *}$ \\
\hline $\mathrm{P} 3 \mathrm{a} \rightarrow \mathrm{T} 3$ & $.58^{* * *}$ & .10 & $.83^{* * *}$ & $.27^{*}$ & $.83^{* * *}$ & $.27^{*}$ & $1.00^{* * *}$ & $.56^{* *}$ \\
\hline $\mathrm{T} 3 \rightarrow \mathrm{P} 3 \mathrm{~b}$ & $.52^{* * *}$ & .00 & $.48^{* * *}$ & $.19^{*}$ & $.48^{* * *}$ & $.19^{*}$ & $.84^{* * *}$ & $.60^{* * *}$ \\
\hline $\mathrm{P} 4 \rightarrow \mathrm{T} 4$ & $1.00^{* * *}$ & .00 & $1.00^{* * *}$ & .00 & $1.00^{* * *}$ & .00 & $1.00^{* * *}$ & .00 \\
\hline $\mathrm{C} 1 \rightarrow \mathrm{C} 2^{\mathrm{b}}$ & $.50^{*}$ & .24 & $.89^{*}$ & .76 & $.89^{*}$ & .76 & $.83^{*}$ & .22 \\
\hline $\mathrm{C} 1 \rightarrow \mathrm{C} 3$ & $.50^{* * *}$ & .13 & .11 & .14 & .11 & .14 & .17 & $.33^{*}$ \\
\hline $\mathrm{C} 2 \rightarrow \mathrm{C} 4$ & $.44^{* *}$ & .00 & $.34^{* *}$ & .00 & $.34^{*}$ & .00 & $.33^{*}$ & .00 \\
\hline
\end{tabular}

Note: The results of sequential analyses by Safran, Muran and Samstag (1994) do not appear in Table $1 .{ }^{\text {a }} \mathrm{P} 1=$ the patient produces a withdrawal rupture indicator; T1 = the therapist focuses the patient on his immediate experience; P2 $=$ the patient expresses negative feelings mixed with the indicator; T2 $=$ the therapist facilitates the self-affirmation; $\mathrm{P} 3 \mathrm{a}=$ the patient reveals the block; $\mathrm{T} 3=$ the therapist asks questions about the patient's block; P $3 \mathrm{~b}=$ the patient explores the fear that blocks him from expressing negative feelings; $\mathrm{P} 4=$ the patient asserts himself; $\mathrm{T} 4=$ the therapist validates the self-affirmation. $\mathrm{C} 1=$ pay attention to the rupture indicator; $\mathrm{C} 2=$ explore the rupture experience; $\mathrm{C} 3=$ explore the avoidance; $\mathrm{C} 4=$ self-affirmation. $* * * p<.001 * * p<.01 * p<.05$.

components proved to be significant below .01. $\mathrm{z}$ scores varied from 3.01 to 10.06 . The significance levels for all sequences between components were below .05. z scores varied from 2.28 to 4.24 .

Safran and Muran (1996) and Inck (1995) performed sequen- tial analyses of alliance rupture resolution and non-resolution sessions. The first results of sequential analyses by Safran and Muran (1996) and Inck (1995) pertain to sequences within components. Transitional probability for the sequence between P1 (the patient produces a withdrawal rupture indicator) and T1 
(the therapist focuses the patient on his immediate experience) was $1.00(p<.001)$ in the 4 studies for resolution sessions. For non-resolution sessions, transitional probability was $.92(p$ $<.001)$ in Safran and Muran's (1996) first study and 1.00 ( $p$ $<.001)$ in the 3 other studies. Transitional probabilities for the sequence between P2 (the patient expresses negative feelings mixed with the indicator) and T2 (the therapist facilitates the self-affirmation) varied from $.87(p<.001)$ to $.97(p<.001)$ for resolution sessions and from $.42(p<.001)$ to $.47(p<.001)$ for non-resolution sessions. Transitional probability for the sequence between P3a (the patient reveals the block) and T3 (the therapist asks questions about the patient's block) varied from $.58(p<.001)$ to $1.00(p<.001)$ for resolution sessions and from .10 to $0.56(p<.01)$ for non-resolution sessions. Transitional probability for the sequence between T3 (the therapist asks questions about the patient's block) and P3b (the patient explores the fear that blocks him from expressing negative feelings) varied from .48 to $.84(p<.001)$ for resolution sessions and from .00 to $.60(p<.001)$ for non-resolution sessions. Transitional probability for the sequence between P4 (the patient asserts himself) and T4 (the therapist validates the self-affirmation) in the 4 studies was $1.00(p<.001)$ for resolution sessions and .00 for non-resolution sessions. The second results of sequential analyses concern sequences between components. For resolution sessions, transitional probability for the sequence between $\mathrm{C} 1$ (pay attention to the rupture indicator) and $\mathrm{C} 2$ (explore the rupture experience) varied from .50 ( $p$ $<.05)$ to $.89(p<.05)$ for resolution sessions and from .22 to .76 for non-resolution sessions. Transitional probabilities for the sequence between $\mathrm{C} 1$ (pay attention to the rupture indicator) and C3 (explore the avoidance) varied from .11 to $.50(p<.001)$ for resolution sessions and from .13 to $.33(p<.05)$ for non-resolution sessions. Transitional probability for the sequence between $\mathrm{C} 2$ (explore the rupture experience) and $\mathrm{C} 4$ (self-affirmation) varied from $.33(p<.05)$ to $.44(p<.01)$ for resolution sessions. For non-resolution sessions, transitional probabilities were .00 in the 4 studies. The researchers performed the sequential analyses with Bakeman's (1983) Lag 1 software.

\section{Results Analysis}

Generally, the results of sequential analyses confirm both sequence types (within and between components) for resolution sessions more than for non-resolution sessions. However, the results of sequential analyses confirm the hypotheses of sequences within components more than they do for those between components. In fact, the results of sequential analyses confirm all sequences within the components for resolution and non-resolution sessions alike. Only for resolution sessions do the results confirm sequences between components.

The cognitive model of the therapeutic relationship explains these results. Several academics (Horowitz, 1988; Mahoney, 1982; Safran, Vallis, Segal, \& Shaw, 1986) suggest that central cognitive structures or patterns organize a patient's perception of the meaning of other people's actions. According to Safran (1990) and Safran, Segal, Hill and Whiffen (1990), central cognitive structures are conceptualized into generalized expectations regarding a person's interactions with others or his interpersonal patterns based on past experiences. When these central cognitive structures are dysfunctional, they activate maladjusted interpersonal cognitive cycles where the patient's expec- tations lead to a behaviour that triggers interpersonal consequences, confirming their dysfunctional expectations. For example, further to numerous abandonments, a person expects to be abandoned by others when beginning new relationships. Consequently, the person acts clingy and dependent, which eventually alienates others and confirms his expectations. Another person, who lived in a very critical environment, expects others to be critical of him and will therefore act in an extremely self-justifying manner, which irritates others and eventually provokes the type of criticism that he expects.

According to Safran (1990), when the therapist's actions are consistent with the patient's dysfunctional interpersonal pattern, he perpetuates a dysfunctional cognitive interpersonal cycle. For example, a therapist who responds to a patient's hostility with counter-hostility may confirm the patient's belief that the universe is a hostile place that must be treated with hostility. Furthermore, if the therapist can avoid participating in the patient's interpersonal cognitive cycle, the patient faces a major experiential challenge to his dysfunctional beliefs.

The central mechanism consists of challenging the client's pathological beliefs. The client interprets the questioning of his dysfunctional beliefs in a way that allows him to collaborate with the therapist. Furthermore, interventions that confirm the client's dysfunctional beliefs make it difficult to collaborate with the therapist. For example, a client who thinks others will try to dominate him will have difficulty establishing an alliance with a dominant therapist. A client who sees others as being emotionally unavailable will have trouble establishing an alliance with a therapist who is withdrawn.

Generally, alliance ruptures occur when the therapist's actions confirm the client's dysfunctional cognitive structure. A rupture creates a unique situation that allows exploration of the expectations, beliefs, emotions and evaluation processes that play a central role in the client's dysfunctional interpersonal relationships. For example, a therapist realizes that a client responds to the intervention by withdrawing. Exploring this experience allows the therapist to discover that the client feels he is being treated with condescension, but does not mention it for fear of angering the therapist.

Exploring the interpersonal pattern fits in with the entire resolution process proposed by Safran, Muran and Samstag's (1994) Model 2. The model thus allows the therapeutic alliance to be restored.

\section{Conclusion}

Adolescents in youth centers often undergo treatment against their will. This context seems to make ruptures in the therapeutic alliance between youths and their caseworkers inevitable According to some authors, therapies that include alliance ruptures appear to be more effective than those without ruptures, on condition, however, that the alliance is restored.

The question at the origin of the article is the following: Which models of the alliance rupture resolution process were subjected to experimental investigation? It turns out that very few experimental studies concern models of the resolution process of therapeutic alliance ruptures. Only Safran and $\mathrm{Mu}-$ ran's team conducted a heuristic study on a rupture resolution model that they subjected to experimental investigation. Furthermore, the method had limitations. First, in all the studies, the treatment included a very limited number of sessions. The studies involved 6 therapists and the number of patients proved 
to be very low, varying from 3 to 5 . All these aspects of the method limited generalization of the alliance rupture resolution model.

The researchers used a very heavy process analysis method that did not allow a larger sampling. Is replicating studies a way to resolve the problem? Is it possible to simplify the process analysis method? Inck (1995) attempted to remedy this deficiency by developing the direct identification of resolution components (DIRC). The idea of directly identifying the components seems to be an interesting technique.

According to Safran (personal communication), the team attempts to improve the experimental value of its models by pursuing its work with other patients and therapists. Safran and Muran $(1996,2000)$ also turned towards another technique to identify model components: the Core Conflictual Relationship Theme (CCRT) (Luborsky \& Crits-Christoph, 1990).

The authors of this article also proposed to conduct research that would continue the work by Safran and his colleagues in a psychosocial intervention context among youths with adjustment difficulties. They also proposed to rework certain elements of the method, such as the way to select rupture sessions and operationalize model components.

\section{REFERENCES}

Aspland, H., Lewelyn, S., Hardy, Gillian, G. E., Barkham, M., \& Stiles, W. (2008). Alliance ruptures and rupture resolution in cognitive-behavior therapy: A preliminary task analysis. Psychotherapy Research, 18, 699-710. doi:10.1080/10503300802291463

Bakeman, R. (1983). Computing lag sequential statistics: The ELAG program. Behavior Research Methods and Instrumentation, 15, 530535. doi:10.3758/BF03203700

Barrett-Lennard, G. T. (1962). Dimension of therapist response as causal factors in therapeutic change. Psychological Monographs, 76, $1-36$.

Barrett-Lennard, G. T. (1978). The relationship inventory: Later development and adaptations (Nos. 8, 68). JSAS Catalog of Selected Documents in Psychology.

Barrett-Lennard, G. T. (1986). The relationship inventory now: Issues and advances in theory, method, and, use. In L. S. Greenberg, \& W. M. Pinsof (Eds.), The psychotherapeutic process: A research handbook. New York: Guilford Press.

Benjamin, L. S. (1974). Structural analysis of social behavior. Psychological Review, 81, 392-425. doi:10.1037/h0037024

Benjamin, L. S. (1979). Use of structural analysis of social behavior (SASB) and Markov chains to study dynamic interactions. Journal of Abnormal Psychology, 88, 303-319.

doi:10.1037/0021-843X.88.3.303

Benjamin, L. S. (1982). Use of structural analysis of social behavior (SASB) to guide intervention in psychotherapy. In J. C. Anchin \& D. J. Kiesler (Eds.), Handbook of interpersonal psychotherapy (pp. 190-212). New York: Pergamon Press.

Bordin, E. (1979). The generalizability of the psychoanalytic concept of the working alliance. Psychotherapy: Theory, Research, and Practice, 16, 252-260. doi:10.1037/h0085885

Brenner, C. (1979). Working alliance, therapeutic alliance, and transference. Journal of the American Psychoanalytic Association, 27, 136-158.

Bennett, D., Parry, G., \& Ryle, A. (2006). Resolving threats to the therapeutic alliance im cognitive analytic therapy of borderline personality disorder: A task analysis. Psychology and Psychotherapy: Theory, Research and practice, 79, 395-418. doi:10.1348/147608305X58355

Curtis, H. C. (1979). The concept of therapeutic alliance: Implications for the "widening scope". Journal of the American Psychoanalytic Association, 27, 159-192.
Docherty, J. P (1989). The individual psychotherapies: Efficacy, syndrome-based treatments, and the therapeutic alliance. In A. Lazare (Ed.), Outpatient psychiatry: Diagnosis and treatment (2nd ed., pp. 624-644). Baltimore, MD: Williams \& Wilkins Co.

Florsheim, P., Shotorbani, S., Guest-Warnick, G., Barratt, T., \& Hwang, W.-C. (2000). Role of the working alliance in the treatment of delinquent boys in community-based programs. Journal of Clinical Child Psychology, 29, 94-107. doi:10.1207/S15374424jccp2901 10

Freud, S. (1913/1966). On beginning the treatment. In J. Strachey (Ed.), The standard edition of the complete psychological works of Sigmund Freud. London: Hogarth Press.

Frieswyk, S. H., Allen, J. G., Colson, D. B., Coyne, L., Gabbard, G. O., Horowitz, L., \& Newsom, G. (1986). Therapeutic alliance: Its place as a process and outcome variable dynamic psychotherapy research. Journal of Consulting and Clinical Psychology, 54, 32-38. doi:10.1037/0022-006X.54.1.32

Gelso, C. J., \& Carter, J. A. (1985). The relationship in counseling and psychotherapy: Components, consequences, and theoretical antecedents. The Counseling Psychologist, 13, 155-243. doi: $10.1177 / 0011000085132001$

Greenberg, L. S. (1984). A task analysis of intrapersonal conflict resolution. In L. N. Rice, \& L. S. Greenberg (Eds.), Patterns of change: Intensive analysis of psychotherapy process (pp. 67-123). New York: Guilford.

Greenson, R. R. (1965). The working alliance and the transference neuroses. Psychotherapy Quarterly, 34, 155-181.

Greenson, R. R. (1967/77). Technique et pratique de la psychanalyse. Paris: Presses Universitaires de France.

Horvath, A. O. (1994). Empirical validation of Bordin's pantheoretical model of the alliance: The Working Alliance Inventory perspective. In A. Horvath, \& L. S. Greenberg (Eds.), The working alliance: Theory, research and practice (pp. 109-128). New York: Wiley.

Horvath, A. O., \& Greenberg, L. S. (1989). Development and validation of the Working Alliance Inventory. Journal of Counseling Psychology, 36, 223-233. doi:10.1037/0022-0167.36.2.223

Horvath, A. O., \& Symonds, B. D. (1991). Relation between working alliance and outcome in psychotherapy: a meta-analysis. Journal of Counseling Psychology, 38, 139-149. doi:10.1037/0022-0167.38.2.139

Inck, T. A. (1995). Resolving therapeutic alliance ruptures. Unpublished Doctoral Dissertation, New York: Adelphi University.

Klein, M. H., Mathieu-Coughlan, P., \& Kiesler, D. J. (1986). The experiencing scales. In L. S. Greenberg, \& W. M. Pinsof (Eds.), The psychotherapeutic process: A research handbook (pp. 21-71). New York: Guilford.

Le Blanc, M., Girard, S., Kaspi, N., Lanctôt, N., \& Langelier, S. (1995). Les adolescents en difficulté des années 1990. Rapport no. 3 Adolescents protégés et jeunes contrevenants sous ordonnance de la chambre de la jeunesse de Montréal en 1992-1993. Montréal: École de psychoéducation, Groupe de recherche sur les adolescents en difficulté, Université de Montréal.

Lessard, C. (2001). Indicateurs repères sur l'application de la loi sur la protection de la jeunesse 1993-1994 à 1999-2000. Québec: Service des indicateurs et mesure de la performance, Direction de la gestion des information, Ministère de la santé et des services sociaux.

Luborsky, L., \& Crits-Christoph, P. (1990). Understanding transference: The CCRT method. New York: Basic Books.

Luborsky, L. (1976). Helping alliance in psychotherapy. In J. L. Cleghhorn (Ed.), Successful psychotherapy (pp. 92-116). New York: Brunner/Mazel.

Martin, D. J., Garske, M. J., \& Davis, M. K. (2000). Relation of the therapeutic alliance with outcome and other variables: A meta-analytic review. Journal of Consulting and Clinical Psychology, 68, 438-450. doi:10.1037/0022-006X.68.3.438

Mitchell, K. M., Bozarth, J. D., \& Krauft, C. C. (1977). A reappraisal of the therapeutic effectiveness of accurate empathy, nonpossessive warmth, and genuineness. In A. S. Gurman, \& A. M. Razin (Eds.), Effective psychotherapy: A handbook of research (pp. 544-565). New York: Pergamon.

Moseley, D. C. (1983). The therapeutic relationship and its association with outcome. Unpublished Master's Thesis, Vancouver: University 
of British Columbia.

Orlinsky, D. E., Grawe, K., \& Parks, B. K. (1994). Process and outcome in psychotherapy-Noch einmal. In A. Bergin, \& J. S. Garfield (Eds.), Handbook of psychotherapy and behaviour change (4th edition, pp. 270-378). New York: Wiley.

Pauzé, R., Toupin, J., Déry, M., \& Mercier, H. (2000). Portrait des jeunes inscrits à la prise en charge des centres jeunesse du Québec et description des services reçus au cours des premiers mois. In D. R. Cloutier (Ed.), Synthèse du rapport: Les soins aux jeunes en difficulté Qc-411 (pp. 1-8). Québec: Centre jeunesse de Québec.

Pinsof, W. M., \& Catherall, D. R. (1986). The integrative psychotherapy alliance: Family, couple and individual therapy scales. Journal of Marital and Family Therapy, 12, 137-151.

doi:10.1111/j.1752-0606.1986.tb01631.x

Pinsof, W. M. (1995). Integrative problem-centered therapy. New York: Basic Books.

Rice, K. S., \& Wagstaff, K. (1967). Client voice quality and expressive style as indexes of productive psychotherapy. Journal of Consulting Psychology, 31, 557-563. doi:10.1037/h0025164

Rice, L. N., \& Greenberg, L. S. (1984). Future research directions. In L. N. Rice, \& L. S. Greenberg (Eds.), Patterns of change: Intensive analysis of psychotherapy process (pp. 289-308). New York: Guilford.

Rice, L. N. \& Kerr, G. P. (1986). Measures of client and therapist vocal quality. In L. S. Greenberg, \& W. M. Pinsof (Eds.), The psychotherapeutic process: A research handbook (pp. 73-105). New York: Guilford.

Rice, L. N. \& Saperia, E. P. (1984). Task analysis of the resolution of problematic reaction. In L. N. Rice, \& L. S. Greenberg (Eds.), Patterns of change: Intensive analysis of psychotherapy process (pp. 67-123). New York: Guilford.

Rogers, C. R. (1957). The necessary and sufficient conditions of thera- peutic personality change. Journal of Consulting Psychology, 21, 95-103. doi: 10.1037/h0045357

Safran, J. D. (1990). Towards a refinement of cognitive therapy in light of interpersonal theory: I. Theory. Clinical Psychology Review, 10, 87-105. doi:10.1016/0272-7358(90)90108-M

Safran, J. D., \& Muran, J. C. (1996). The resolution of ruptures in the therapeutic alliance. Journal of Counseling and Clinical Psychology, 64, 447-458. doi:10.1037/0022-006X.64.3.447

Safran, J. D., \& Muran, J. C. (2000). Negotiating the therapeutic alliance: a relational treatment guide. New York: Guilford.

Safran, J. D., Crocker, P., McMain, S., \& Murray, P. (1990). Therapeutic alliance rupture as a therapy event for empirical investigation. Psychotherapy, 27, 154-165. doi:10.1037/0033-3204.27.2.154

Safran, J. D., Greenberg, L. S., \& Rice, L. N. (1988). Integrating psychotherapy research and practice: Modeling the change process. Psychotherapy, 25, 1-17. doi:10.1037/h0085305

Safran, J. D., Muran, J. C., \& Samstag, L. W. (1994). Resolving therapeutic alliance ruptures: A task analytic investigation. In A. O. Horvath \& L. S. Greenberg (Eds.), The working alliance: Theory, research and practice (pp. 225-255). New York: Wiley.

Safran, J. D., Segal, Z. V., Hill, C., \& Whiffen, V. (1990). Refining strategies for research on self-representations in emotional disorders. Cognitive Therapy and Research, 14, 143-160. doi:10.1007/BF01176206

Safran, J. D., Vallis, T. M., Segal, Z. V., \& Shaw, B. F. (1986). Assessment of core cognitive processes in cognitive therapy. Cognitive Therapy and Research, 10, 509-526. doi:10.1007/BF01177815

Sterba, R. (1934). The fate of the ego in analytic therapy. International Journal of Psychoanalysis, 15, 117-126.

Zetzel, E. R. (1956). Current concepts of transference. International Journal of Psychoanalysis, 37, 369-376 